Article

\title{
Professional Car Drivers' Attitudes toward Technical, Marketing and Environmental Characteristics of Engine Oils: A Survey Study
}

\author{
Artur Wolak $^{1, *}$, Kamil Fijorek ${ }^{2}\left(\mathbb{D}\right.$ and Grzegorz Zając ${ }^{3}$ (D) \\ 1 Department of Quality and Safety of Industrial Products, Institute of Quality and Product Management \\ Sciences, Cracow University of Economics, 27 Rakowicka St., 31-510 Cracow, Poland \\ 2 Department of Statistics, College of Economics, Finance and Law, Cracow University of Economics, \\ 27 Rakowicka St., 31-510 Cracow, Poland; kamil.fijorek@uek.krakow.pl \\ 3 Department of Power Engineering and Transportation, Faculty of Production Engineering, University of Life \\ Sciences in Lublin, 28 Gleboka St., 20-612 Lublin, Poland; grzegorz.zajac@up.lublin.pl \\ * Correspondence: artur.wolak@uek.krakow.pl; Tel.: +48-12-293-78-41
}

Received: 22 February 2020; Accepted: 18 April 2020; Published: 21 April 2020

\begin{abstract}
The aim of the article was to analyze the decision-making process of professional drivers regarding the choice of new engine oil with additional attention to the eco-friendliness aspect of the product. Survey data were collected from Polish consumers, using a self-administered questionnaire. The main data analysis tools used in the study were finite mixture models. It was found that professional drivers do not constitute a single homogenous group. They cluster into two segments with differing importance profiles. The largest consumer segment, over $80 \%$ of consumers, consider the quality classification, viscosity classification, and OEM specifications as the most important criteria during the decision-making process. The importance of oil being environmentally friendly is a factor moderately differentiating the subgroups. In the first segment, a strong preference for engine oil with the same technical parameters as the previously purchased one, but additionally marked as environmentally friendly, was indicated by $29 \%$ of the respondents, whereas in the second segment by only $15 \%$. The analysis of the consumer decision-making process showed that there is a need to put additional efforts to provide easily accessible and clearly visible technical specifications on the product label. The vast majority of professional drivers surveyed were mainly guided by such specific data in their purchasing process. Engine oils and specially used engine oils belong to a group of products that are considered to have a major negative impact on the environment. As a result, more research is needed into the sustainability of this class of products. The shift into the eco-friendly production, exploitation and subsequent management of engine oils may cause a profound effect on petroleum energy markets.
\end{abstract}

Keywords: engine oil sustainability; oil market; consumer behavior; consumer segmentation; eco-friendliness; professional drivers; model-based clustering

\section{Introduction and Theoretical Background}

Consumer decision-making processes have been in the scope of scientific and academic interest since the 1960s. [1-6]. The research results in this area help understand the markets and the mechanisms of the behavior of different market entities (sellers, consumers, competitors). Making purchasing decisions is a complex cognitive process involving many factors, among which the main role is played by searching for and processing information. Studies show [4] that a significant proportion of purchases made by consumers are planned behaviors. With the development of information technology and easier access to information, a significant proportion of customers have a greater 
knowledge of products. At the same time, the excess of information associated with the large number of products available on the market often makes consumers feel confused and impedes decision-making. According to [7], the key process behind making purchasing decisions is the integration process, in which the acquired knowledge is combined to assess two or more alternative behaviors and choose one of them. Consumer engagement in purchasing decisions is also a direct result of the reaction to marketing and advertising stimuli [8]. Highly engaged consumers are more interested in the product and are more likely to buy it. Companies have long been analyzing buyer decision-making processes to find answers to the most basic questions such as what, how, how much, when, why, and where the consumers buy [9].

In recent years, dramatic changes in the global state of the environment, increasing pollution as well as environmental health aspects have become one of the most important contemporary social problems. The growing ecological awareness is the main driving force for introducing various activities directed towards the prevention of adverse environmental changes [10]. Moreover, relatively recently in both developed and developing countries, consumer care for the natural environment has become a vital part of purchasing processes; and consequently, has led to changes in many aspects of the functioning of enterprises, their marketing policies, and business strategies [11]. Enterprises that introduce environmentally friendly products typically achieve increased sales [12,13], a higher level of employee engagement [14], greater customer satisfaction [11,15], and improved company brand image $[16,17]$. According to one definition, an environmentally friendly product is "a product that has been manufactured using ingredients that are free of toxic substances and following environmentally friendly procedures, and which as such is certified by a recognized organization" [18]. Consumers are increasingly making their buying decisions taking into account the principles of sustainable development, as well as being aware of the consequences of the impact of their decisions on their own health and the natural environment. That is why they have begun to turn to companies that offer environmentally friendly products and services $[19,20]$, increasingly preferring sustainable alternatives. This strongly motivates companies to offer environmentally friendly goods, which has lately become almost a matter of surviving on the market [21].

An important source of problems with the state of the natural environment is the intense development of various branches of industry (the automotive industry included), which is associated with an increase in the pollution of the environment by oil and petroleum products [22,23]. Engine oils belong to the class of products that pose an environmental threat throughout their entire life cycle. That is why, eco-friendly engine oil should be such from the very design stage through production, storage, transport, use, to the end-of-life management. One of the most important issues concerning the rapid development of the automotive industry is the high proportion of lubricating oils lost in the environment. Lubricating oils are used primarily to reduce friction between moving machine parts, minimize their wear, improve efficiency, and save fuel and energy. During operation, lubricating oils are contaminated and gradually degraded, which means that they lose their useful properties and should be replaced. Used oils become waste oils and are classified as hazardous waste [24]. However, waste oils are not only generated by various industries but by road, air and sea transport as well. In this context, the automotive sector is particularly burdensome for the environment, which through a continuous increase in the number of vehicles leads to greater consumption of lubricating oils. It is estimated that about $56 \%$ of the total demand for lubricating oils comes from the automotive sector. Yet, not all engine oils are recovered after their service life, as about $50 \%$ of the oil used in engines is lost as a result of evaporation or combustion [25]. It is also worth noting that some of the oil may remain on the walls of the packaging and it can be thus introduced directly into the environment with it. The remaining part of the oil is collected at the decommissioning stage and becomes waste oil. Waste oils are collected mainly in car service stations or private (residential) garages during an oil change. Considering the environmental protection, the replacement of engine oil in professional garages or car service stations is much more advantageous because it ensures a correct and controlled collection as well as waste management. This is a particularly important issue in developing countries, which usually do not 
have adequate procedures for the disposal and recycling of waste oils [26,27]. However, it cannot be said that the problem has been entirely resolved in developed countries either. In Europe, waste oils are the largest stream of liquid hazardous waste [28]; whereas, in the US, less than $60 \%$ of waste oils are recycled [29]. An oil change performed in a private garage setting may lead to improper management. If engine oil is stored in the user's own garage for a longer period of time and in an unprotected manner; if it is poured into the storm sewer [30,31], directly into soil or wastewater sewers [32], it may cause significant pollution of groundwater and soil [10]. When engine oil is spilled, it migrates down through the soil, reaching groundwater, and then spreads sideways because of capillary forces and soil heterogeneity. During a non-professional oil change, uncontrolled incineration accompanied by metal and PAH (polycyclic aromatic hydrocarbons) emissions may also take place $[33,34]$, which are then generally adsorbed by airborne dust to eventually settle in soil and water.

Contaminants found in waste oils have an adverse effect on both human health and the environment, and the degree of impact on the environment depends on three basic factors: the chemical composition of the oil, the conditions of its operation in the machine, and the methods of its management [35]. The presence of degraded additives, waste and degradation by-products in waste oils translates into an increase in their toxicity and harmfulness to human health and the environment. Used engine oils contain PAHs, oil conditioners, antioxidants, trace levels of chlorinated solvents, polychlorinated biphenyls (PCBs) [36,37], and heavy metals [31,38]. Waste oils have been shown to be mutagenic and teratogenic. Furthermore, fetotoxic and genotoxic effects have also been reported [39]. Used oils are therefore considered one of the most dangerous types of pollutants.

Another vital aspect of the issue is its economic dimension. A recycled lubricating oil preserves valuable resources and reduces $\mathrm{CO}_{2}$ emissions [32,40]. About 67 liters of crude oil are needed to produce 1 liter of lubricating oil but in the case of re-refining, only 1.6 liters of used oil are needed to recover 1 liter of base oil [24]. This example illustrates the importance of responsible oil management at all stages of its use, collection, and reuse. A rational economy is also supported by appropriate legal regulations regarding the management of used lubricating oil, e.g., the Waste Framework Directive 2008/98/EC [25]. Another consumer behavior causing economic and environmental problems is the fact that oil users do not often make optimal decisions regarding oil change intervals. Some of them change oil too early, thus generating unnecessary costs for themselves and the environment, mainly due to only partial use of the oil's potential. Some of them change the oil too late, degrading the technical condition of the engine, exposing themselves and the environment to the negative consequences of unnecessary vehicle repairs, and making the oil more harmful to the environment, thus hindering its recycling.

As mentioned above, more and more consumers are realizing the wider consequences of their purchasing decisions. Consumers are beginning to understand that by acting rationally with used oils, they can have a positive impact on the state of the environment. In the decision-making process, a responsible consumer tries to take into account the economic, social and environmental aspects, and to conform to the principles of sustainable development throughout the entire consumer chain [41], such as the type and number of products purchased, their use and disposal. In addition, as suggested by $[13,42]$, buying environmentally friendly products is one of several activities by which consumers can embody their ideals regarding the active protection of the environment. They now recognize that not only the manufacturer but also the consumer should be responsible for the environmental aspects of the use of engine oils. Oil producers need to continue to increase their efforts to better inform consumers which oils are environmentally friendly or at least neutral to the environment.

In the literature, there is a large body of research on consumer environmental behavior in relation to everyday products such as food [43-45], cleaning supplies [46] or products that have a labeling policy regulated by law, e.g., household appliances [47]. However, there are no such studies for engine oils intended for use in passenger cars. In their previous study [48], the authors of this article examined selected aspects of the consumer decision-making process regarding the choice of new engine oil. The research focused on regular drivers, i.e., people who use cars to meet their 
mobility and transportation needs. Professional drivers comprise a much smaller group in society; however, compared to regular drivers, they generally use their vehicles more intensively. Taxi drivers constitute an important segment of professional drivers. Passenger transport is the main task of the taxi drivers. In order to provide an economic and safe service, they have to maintain the proper technical condition of the vehicle [49]. They care about avoiding car breakdowns to maintain earnings continuity. Therefore, they need the necessary skills to recognize early symptoms of vehicle failure [50]. Taxi drivers also often exchange experiences regarding the use of vehicles with other professional drivers and thus improve the quality of their car's maintenance [51]. These technical characteristics mostly distinguish taxi drivers from regular drivers who are less likely to devote as much time and attention to proper car maintenance, with careful engine oil selection not being an exception.

The aim of this paper is to present the research results on the decision-making processes of professional drivers when they choose a new engine oil. Unlike in the previous study [48], the analysis was extended to include the environmental aspects, and especially in this context, the article fills the gap in the literature as indicated above.

\section{Materials and Methods}

\subsection{Survey Design}

The study covered a group of 144 taxi drivers, working in one of the largest Polish cities. Limiting the study to one professional group was intentional and aimed at gaining more thorough insights into the opinions and views of the respondents. From this perspective, it can be concluded that the sample size of 144 is large in relation to the population size and the survey is approximately an exhaustive study. This, in turn, suggests that the data analysis will be characterized by a high level of results stability. The research was carried out using a survey method, and the questionnaires were provided to respondents electronically. The respondents were reached via associations of professional drivers, particularly those enjoying high popularity in the professional taxi community. It can be assumed that due to this procedure, the respondents approached the questionnaire in a more responsible way, thus increasing the reliability of the source data.

The questionnaire contained 32 questions, including 26 closed and 6 open ones. The design of the questionnaire was preceded by an in-depth literature analysis to formulate survey questions that correctly reflect the multi-faceted structure of the phenomenon under study. A detailed discussion of this aspect is described in the article [48]. The two questions that formed the principal basis of the analysis concerned the importance of the criteria determining the choice of the engine oil brand and an indication of the willingness to buy engine oil with the same technical parameters as the one previously bought but marked as environmentally friendly. In the first area of research, the respondents assessed the subjectively perceived importance of 13 different items on a five-point scale (unimportant, not very important, quite important, important, very important). The following aspects were assessed: oil price, brand loyalty, brand familiarity, OEM specifications (e.g., VW, MB, GM, etc.), the scope of information provided on the oil label, qualitative classification (e.g., API, ACEA), viscosity grade (SAE J300, e.g., 5W-30), radio and TV ads, recommendations of the supplier, recommendations of the car manufacturer, recommendations of the authorized service center, recommendations of the local garage/car service station, recommendations provided by the family and friends. In the latter area of the research, the respondents indicated if they declare unconditional support for eco-friendly oil, conditional (e.g., lower price) or expressed lack of interest in this kind of product.

\subsection{Research Hypotheses}

The following two main research hypotheses were formulated. Hypothesis A (HA): "Professional taxi drivers do not constitute a single homogenous group. They cluster into an a priori unknown number of segments with differing importance profiles." This hypothesis will be investigated using a model-based clustering algorithm. It is necessary to point out that there is no prior evidence to support 
this hypothesis. It is probable that due to the narrow definition of the population, respondents actually constitute a homogenous group. As a result, either acceptance or rejection of HA is equally probable. Hypothesis B (HB): "If taxi drivers cluster into the multiple subgroups (HA is accepted), the importance of oil being environmentally friendly is a factor differentiating the subgroups."

\subsection{Data Analysis Methods}

The finite mixture model was used to search for clusters in data. The finite mixture model with $K$ components is defined as:

$$
\begin{gathered}
h(y \mid x, \psi)=\sum_{\mathrm{k}=1}^{K} \pi_{\mathrm{k}} f\left(y \mid x, \theta_{\mathrm{k}}\right) \\
\pi_{\mathrm{k}} \geq 0, \sum_{\mathrm{k}=1}^{K} \pi_{\mathrm{k}}=1
\end{gathered}
$$

where $y$ is a univariate or multivariate dependent variable with conditional density $h, x$ is an optional vector of independent variables, $\pi_{\mathrm{k}}$ is the prior probability of component $k, \theta_{\mathrm{k}}$ is the component-specific parameter vector for the density function $f$, and $\psi=\left(\pi_{1}, \ldots, \pi_{K}, \theta^{\prime}{ }_{1}, \ldots, \theta^{\prime}{ }_{K}\right)^{\prime}$ is the vector of all parameters. For example, for multivariate normal $f$ and $x \equiv 1$, a mixture of Gaussians, also known as Gaussian model-based clustering is obtained. The posterior probability that observation belongs to class $j$ is given by

$$
P(j \mid x, y, \psi)=\frac{\pi_{j} f\left(y \mid x, \theta_{j}\right)}{\sum_{\mathrm{k}=1}^{K} \pi_{\mathrm{k}} f\left(y \mid x, \theta_{\mathrm{k}}\right)}
$$

The posterior probabilities can be used to segment data by assigning each observation to the class with maximum posterior probability. In the above formula, $f\left(\cdot \cdot, \theta_{\mathrm{k}}\right)$ is referred to as mixture components or classes, and the groups in the data induced by these components as clusters.

The mixture is assumed to consist of $K$ components, where each component follows a parametric distribution. Each component has a weight assigned, which indicates the a priori probability for the observation to come from this component and the mixture distribution is given by the weighted sum over the $K$ components [52]. The log-likelihood of a sample of $\mathrm{N}$ observations cannot be maximized directly. The most popular method for maximum likelihood estimation of the parameter vector $\psi$ is the iterative EM algorithm [53]. The E and M steps are repeated until the likelihood improvement falls under a small pre-specified threshold. During the described process, as the EM algorithm converges only to the local maximum of the likelihood, it should be run repeatedly using different starting values [54]. In real applications, the number of components $(K)$ is unknown and has to be estimated. This can be achieved by fitting models with an increasing number of components and then comparing them using the widely known Bayesian Information Criterion (BIC). When choosing from several models, the one with the lowest BIC is preferred as in this case lower BIC implies better fit. The strength of the evidence against the competing model can be summarized as a difference (delta) in the BIC between the two models: $\triangle \mathrm{BIC}$ from 0 to 2 - almost no evidence, 2 to 6 - positive evidence, 6 to 10 - strong evidence, above 10 - very strong evidence [55].

\section{Results}

\subsection{Characteristics of the Sample}

As mentioned in the introduction, the survey was addressed to taxi drivers. A much larger representation of men in the study $(91 \%)$ is consistent with the proportions that occur in this occupational group and reflects the distribution in the population. As many as $83 \%$ of the interviewees were between the age of 18 and 50 years old, with the range up to 30 years old (38\%) being the most frequent. $23 \%$ of the respondents were between $31-40$ years old, while $17 \%$ were above 51 years old. The majority of the respondents $(79 \%)$ had completed a bachelor's or master's degree. Primary education $(14 \%)$ or 
working and studying (7\%) was indicated by $21 \%$ of the respondents. $13 \%$ of the respondents travel to their workplace from rural or suburban areas. $78 \%$ of the cars used by the taxi drivers had the overall mileage above $150 \mathrm{k} \mathrm{km}(150,000 \mathrm{~km})$, with the typical range $200-250 \mathrm{k} \mathrm{km}(31 \%) .15 \%$ of the cars had mileage below $100 \mathrm{k} \mathrm{km}$ and about $17 \%$ above $300 \mathrm{k} \mathrm{km.} 68 \%$ of the cars were manufactured after the year 2005 (age below 15 years), with the range 2005-2009 (age between 10-15 years) (37\%) being the most frequent. About $12 \%$ of taxi drivers drive relatively new cars (below 5 years old). $3 \%$ of interviewees drive cars older than 18 years old (year of production before 2000). Considering both criteria at the same time, i.e., vehicle age and mileage, it can be said that most of the taxis were $10-15$ years old with mileage from $100 \mathrm{k}$ up to $300 \mathrm{k} \mathrm{km}$. $41 \%$ of the respondents use one of the following four car brands to transport their clients: Skoda (14\%), Opel (10\%), Ford $(10 \%)$ or Toyota $(9 \%) .55 \%$ of the respondents had cars with a diesel engine, $45 \%$ indicated having cars with a gasoline engine. In turn, $81 \%$ of the cars were equipped with an engine capacity below $2.00 \mathrm{dm}^{3}$, with a range of $1.51-2.00 \mathrm{dm}^{3}(64 \%)$ being the most frequent.

The research results show that $92 \%$ of the respondents declared having at least basic knowledge of engine oils and their technical aspects-the majority $(67 \%)$ of the taxi drivers surveyed admitted having basic knowledge, whereas $25 \%$ indicated extensive knowledge in this field. All of the respondents agreed that it is necessary to change engine oil in order to prevent oil and engine wear ("Do you think it is necessary to change the engine oil?" - $100 \%$ said yes). The question aiming to establish the respondents' opinions on the best oil change interval brought the following results: the vast majority $(70 \%)$ declared changing the oil after driving $10-15 \mathrm{k} \mathrm{km}$. As many as $12 \%$ of the drivers admitted changing oil at slightly higher kilometer intervals $(15-20 \mathrm{k} \mathrm{km})$. For comparison purposes, only $62 \%$ of regular drivers [56] change engine oil after driving $10-20 \mathrm{~km}$. In the study, $6 \%$ of taxi drivers either change the oil after traveling less than $10 \mathrm{k} \mathrm{km}$ or change the oil during compulsory servicing according to the car service book. $4 \%$ of the respondents declared performing oil changes at different intervals, without paying attention to the service book dates $(2 \%)$, or drivers declaring oil change after exceeding $20 \mathrm{~km}(2 \%)$. In contrast, $3 \%$ of the respondents change the oil every year, regardless of the number of kilometers traveled. The vast majority $(71 \%)$ change oil either in the local garage/car service station $(60 \%)$ or in authorized service centers (ASC) $(11 \%)$. On the other hand, the remaining respondents $(29 \%)$ declared an oil change in their own garage or in the garage of their acquaintance. These results suggest that the studied group is largely homogeneous both in terms of declared knowledge and oil change interval. This may, in turn suggest that the HA research hypothesis will be rejected and that the homogeneity of respondents in terms of the importance of the criteria for choosing a new engine oil will also be found. In the next section of the article, the results of the cluster analysis performed to verify the HA and HB hypotheses are presented in more detail.

\subsection{Model-Based Clustering Results}

As explained in the "Material and Methods" section, a mixture model was fitted to the data introduced in the "Survey Design" section. To avoid local maximum in the EM algorithm, the optimization process was restarted 100 times using random initialization. The number of components $K$ from 1 to 7 was investigated. The best solution with respect to the log-likelihood for each of the different numbers of components was obtained [57] and model selection was made using information criteria (BIC) [58]. The especially interesting case is $K=1$. If selected by the BIC, this would mean that the data favor the hypothesis of one homogenous group. The results were as follows (K: BIC) - 1: 2320, 2: 2203, 3: 2216, 4: 2242, 5: 2274, 6: 2315, 7: 2361. The BIC (2203) strongly favored a mixture model with two segments as the best one, since the BIC for $K=2$ is more than 10 points smaller than the BIC for $K$ greater than 2 . Moreover, the BIC value for one cluster $(K=1)$ is over 100 points higher than the BIC value for $K=2$. This finding directly leads to the acceptance of Hypothesis A.

Figure 1 illustrates the results of the model-based segmentation. Each panel depicts one segment. In the header of a panel, the size of a given segment is provided. Each row represents one of 14 criteria. 
The red markings are the same in each panel and serve as a benchmark profile, as this is an important profile constructed under the assumption of no segmentation. For the first 13 criteria, grey bars represent the probability of choosing given criteria as important or very important by a member of a segment. For a question about oil environmental aspects, it is the probability of choosing the unconditional willingness to purchase an eco-friendly oil.

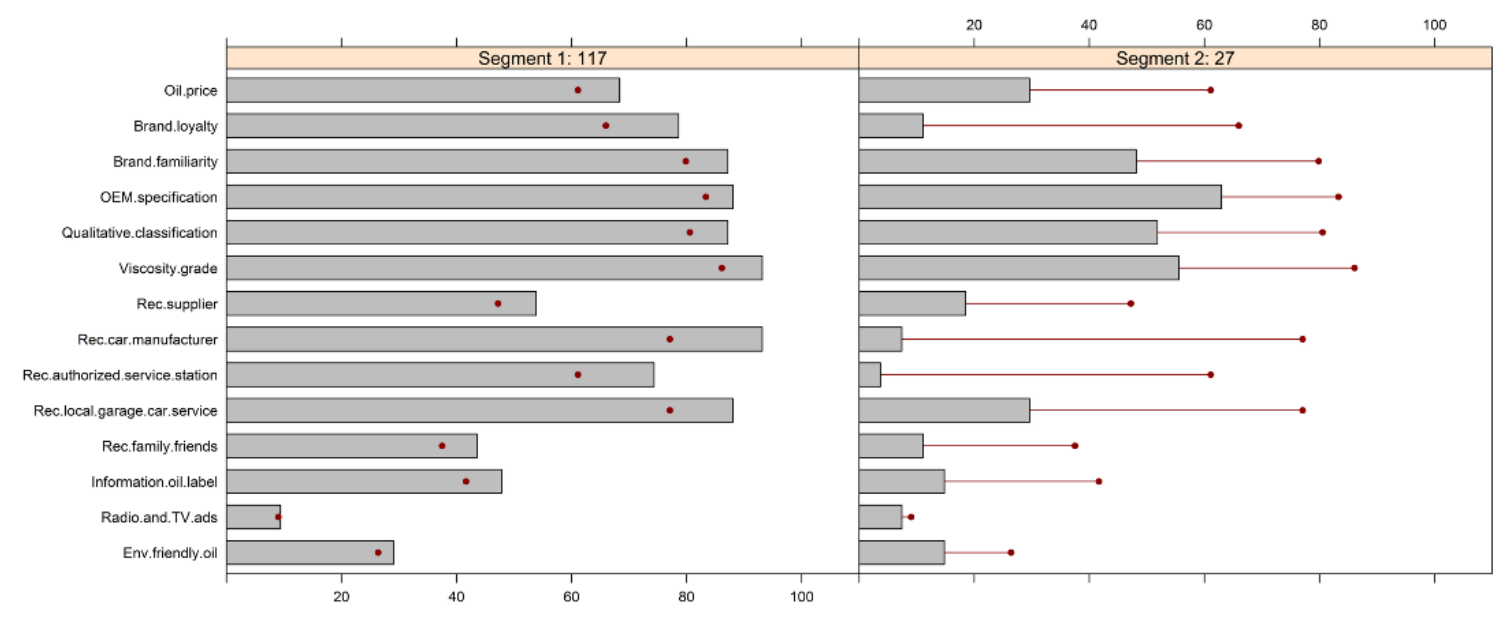

Figure 1. Results of model-based clustering (2 segments).

As shown in Figure 1, segment 1 is the largest one and contains 117 drivers ( $81 \%$ of the respondents) for whom the most important factors in the selection of engine oil were: information about the viscosity classification and the car manufacturer's recommendations (93\% probability that the members of this segment consider the indicated criterion as important or very important), recommendations of local garages, qualitative classification, OEM specifications, and brand familiarity (87-89\%). This group includes drivers who can be described as "rational users". They pay attention to technical parameters (viscosity, quality, OEM specifications), they rely on the recommendations of car manufacturers and employees of local garages. What is more, they do not consider radio and television advertisements as important $(91 \%)$. Drivers from segment 2 (19\% of total) also pay attention to technical aspects, but to a lesser extent than those in segment 1 . The distinguishing feature of this segment is the low level of importance of any recommendations in the process of purchasing a new engine oil. They pay the least attention to ASC recommendations $(10 \%)$ and the recommendation of car service stations/local garages reached $30 \%$. For this group of drivers, brand loyalty $(13 \%)$ and information provided on the oil label (17\%) are equally of little importance. It is worth noting that though two clusters of the respondents were obtained, the first of them is dominant - it comprises as many as 117 drivers out of 144 respondents. Thus, the heterogeneity of professional drivers is visible, but it manifested itself by the emergence of one small niche of drivers.

Referring to Hypothesis B, it can be stated that a strong preference for engine oils with the same technical parameters as the previously bought oil, but additionally marked as environmentally friendly, was indicated by $29 \%$ of the respondents from segment 1 . However, in segment 2 , this percentage was much lower and amounted to only $15 \%$. Thus, Hypothesis B was confirmed. It seems that for professional drivers clustered in the second segment, only strictly technical parameters of oils play any role in purchasing decisions. Due to its importance, the issue of the oil's environmental friendliness requires more in-depth analysis. Table 1 shows that there is a statistically significant $(p=0.003)$ relationship between the propensity to choose an oil with the same technical parameters, but marked as environmentally friendly, and the declared importance of the low engine oil price. Taxi drivers for whom the low oil price is very important or important (58\% and 50\%) declared their interest in environmentally friendly oils, assuming that their price would be lower. A strong preference for oils marked as environmentally friendly was declared by about $40 \%$ of drivers for whom the price in the purchasing process is either of little importance or of no importance at all. 
Table 1. Distribution of drivers' propensity to buy environmentally friendly engine oil conditionally on the declared importance of the low oil price.

\begin{tabular}{cccccc}
\hline If you had to Choose between two & \multicolumn{4}{c}{ Engine Oil Price Importance } \\
$\begin{array}{c}\text { Otherwise Technically Identical Engine } \\
\text { Oils would you Choose the Oil Labeled as } \\
\text { the Environmentally Friendly? }\end{array}$ & Unimportant & $\begin{array}{c}\text { Not Very } \\
\text { Important }\end{array}$ & $\begin{array}{c}\text { Quite } \\
\text { Important }\end{array}$ & Important & $\begin{array}{c}\text { Very } \\
\text { Important }\end{array}$ \\
\cline { 3 - 6 } yes & $40 \%$ & $41 \%$ & $20 \%$ & $15 \%$ & $17 \%$ \\
yes, but only if the price was lower & $7 \%$ & $12 \%$ & $22 \%$ & $50 \%$ & $58 \%$ \\
no, I don't trust products labeled as ecological & $20 \%$ & $15 \%$ & $25 \%$ & $7 \%$ & $8 \%$ \\
no, other reasons & $33 \%$ & $32 \%$ & $33 \%$ & $28 \%$ & $17 \%$ \\
\hline
\end{tabular}

Source: own research.

No statistical significance was obtained for the relationship between the degree of interest in environmentally friendly oils, the age of respondents and the age of the car. However, it was noticeable that the largest support for oils marked as environmentally friendly is among respondents aged $40-49$ years $(41 \%)$, whereas the smallest among drivers under 30 years of age $(14 \%)$. Drivers from both age groups also declared, respectively, the smallest and largest level of distrust towards eco-friendly products $(9 \%-40-49 ; 20 \%$ - below 30$)$. In the case of car age analysis, it can be said that the largest definite interest in eco-friendly products $(35 \%)$ was indicated by the respondents with vehicles that were under 10 years, while the smallest $(18 \%)$ by owners of cars older than 15 years. The opposite situation was obtained for the answer "yes, but only if the price was lower": $36 \%$ of the owners of older cars (over 15 years) as opposed to $17 \%$ of the owners of newer cars (under 10 years). More than a quarter (26\%) of the owners of 10-15-year-old vehicles declared a strong interest in eco-friendly engine oils, whereas $32 \%$ stated they would consider buying such oil if it was cheaper. The correlation with the car mileage almost reached statistical significance $(p=0.078)$. The drivers whose cars had mileage over $300 \mathrm{k} \mathrm{km}$ were generally less interested in oils marked as environmentally friendly as $37 \%$ of the respondents in this group admitted that they are not interested.

In the next part of the data analysis, the segmentation results obtained for professional drivers will be briefly compared to the results of the segmentation of regular drivers, which were the subject of analysis in the article [48]. For regular drivers, the division into four segments was optimal. As a result, it was decided that for comparison purposes, the professional drivers would also be divided into four segments (Figure 2), despite a less favorable BIC value for $K=4$. A noticeably larger number of segments among regular drivers suggests that professional drivers are a much more homogeneous group. In addition, the criterion of the environmental friendliness of oil was not taken into account in this analysis, as it was not tested for ordinary drivers.

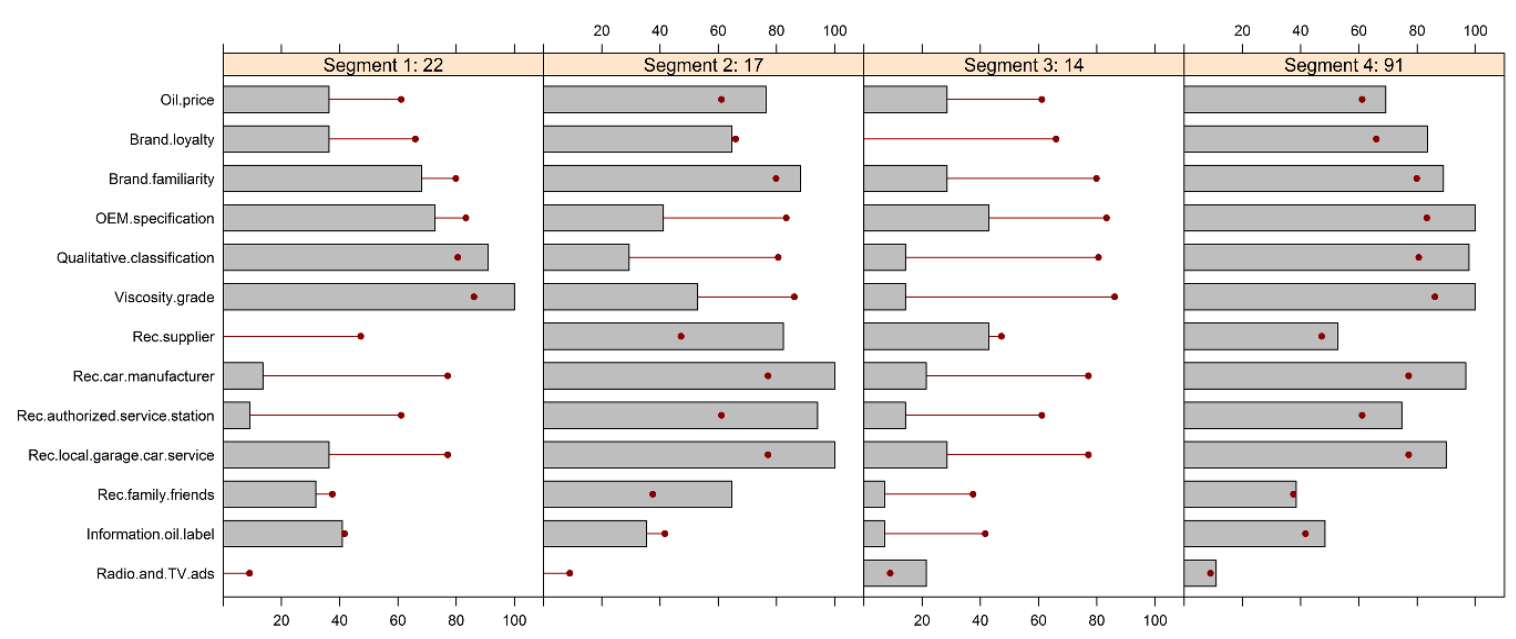

Figure 2. Results of model-based clustering (4 segments). 
Segment 1 drivers (15\% out of 144 drivers) are distinguished by a very low level of confidence in any recommendation sources. An extreme example of this is the fact that $100 \%$ of the respondents consider the recommendations of engine oil sellers to be of no importance in the purchasing process. Segment 2 consists of 17 drivers (12\%). Only 35\% of them believe that the technical aspects of oil (qualitative classification) are an important element when deciding to buy engine oil. Similarly, to the drivers from other segments, they declared that they never took TV/radio advertisements into account when buying engine oil. The drivers from segment 2 can be described as "trusting consumers" because they primarily pay attention to the recommendations of ASCs, local garages, and sellers. Segment $3(10 \%)$ is made up of the respondents for whom all assessed criteria are of little importance. Only oil seller's recommendations and OEM specifications (around 40\%) can be considered as partially important purchasing criteria in this segment. The presence of similar consumer segments is also noticeable for other types of products. This is indicated by studies [2,59-61], in which the authors emphasize that a proportion of consumer purchases does not involve complex decision-making. Some consumers are not motivated enough to engage in a great deal of decision-making at the time of purchase when the product is purchased repeatedly or is deemed relatively unimportant. Segment 4 $(63 \%)$ comprises professional drivers who pay special attention to the technical parameters of oils (viscosity, quality, OEM specifications) and who rely on the recommendations of car manufacturers and employees of local garages/service stations.

In the next stage of the analysis, segment 4 - the largest of the four segments representing professional drivers - will be compared with the largest segment of regular drivers (Figure 3). The appropriate results were taken from the study [48].
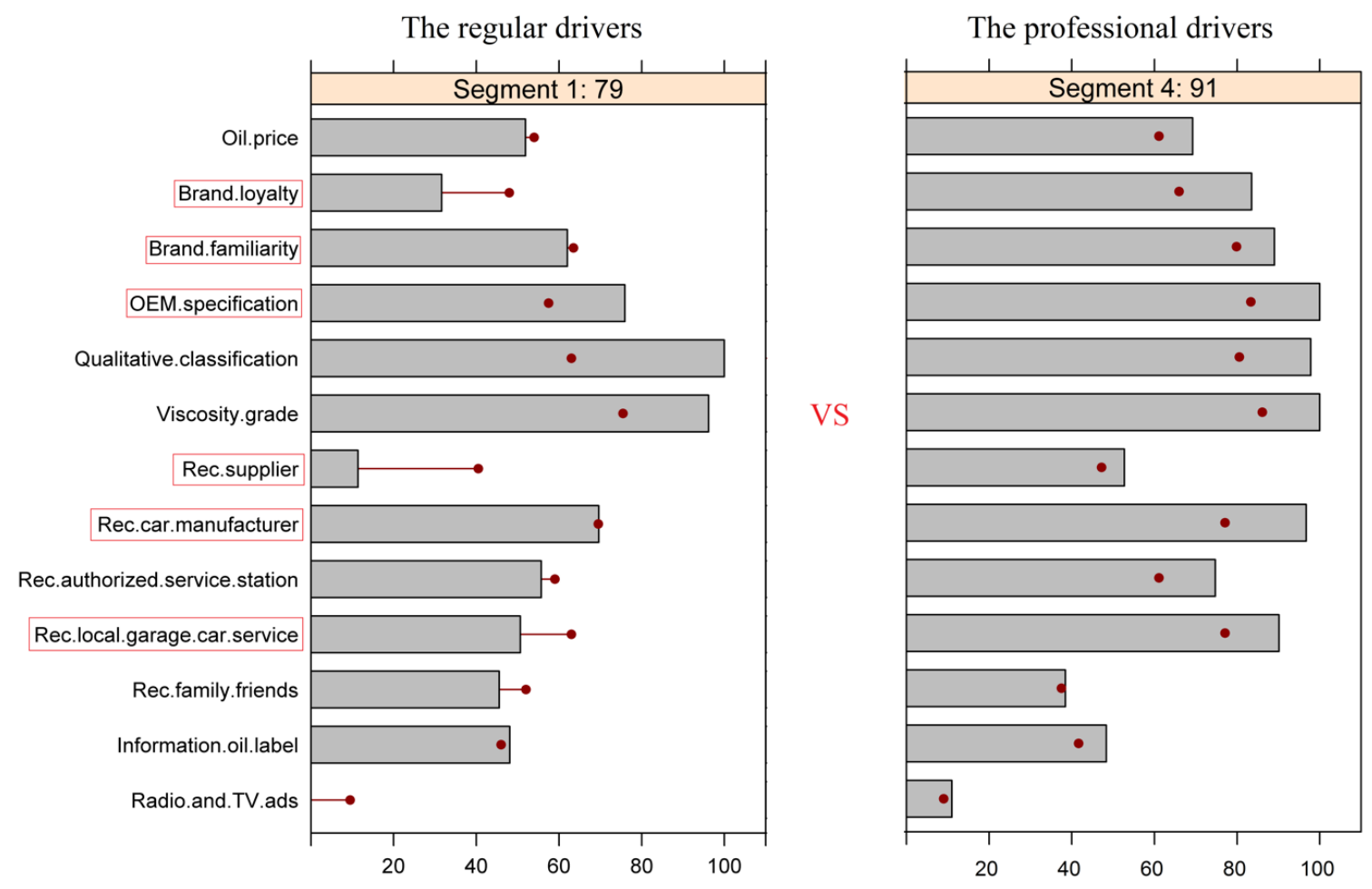

Figure 3. Comparison of the largest segments of regular drivers and professional drivers.

Figure 3 highlights the criteria for which the largest differences between the two segments are observed. These are brand loyalty ( $33 \%$ vs. $84 \%$ ), oil seller's recommendations ( $12 \%$ vs. $53 \%$ ), and local garage recommendations ( $51 \%$ vs. $90 \%$ ). In both groups, almost $100 \%$ probability was obtained that the segment members consider qualitative classification as an important or very important criterion. A similar situation was observed for the viscosity classification ( $96 \%$ vs. $100 \%)$. Information on the 
packaging of engine oil is important to a similar degree ( $48 \%$ vs. $49 \%$ ) for both groups of drivers. Professional drivers $(69 \%)$ pay more attention to the price of oil than regular drivers $(53 \%)$.

\section{Discussion}

The literature does not provide conclusive evidence as to whether consumers are willing to pay more for environmentally friendly products. The results presented by Biswas and Roy suggest that the price, availability, and quality of products have an impact on consumer decisions regarding the purchase of eco-friendly products [62]. Similar conclusions can be drawn from the research presented in $[63,64]$, where it is shown that consumers accepting a higher price of environmentally friendly products want to reward companies engaged in environmental protection. In turn, Ali and Ahmad [65] provided partly different conclusions, indicating that consumers were more willing to buy eco-friendly goods if such products were competitive in terms of price and quality compared to traditional ones. However, among consumers who were concerned about the state of the environment, there was more acceptance of a higher price for eco-friendly products. According to the study by Pars et al. [66], 73\% of customers were willing to accept a price increase for a meal served in a restaurant that engages in responsible environmental practices. However, only half of the customers were willing to accept a price increase of at most $5 \%$. With a larger price increase (up to $10 \%$ ), only $15 \%$ of customers retained that opinion.

Similarly, to the above, it can be stated that not all professional drivers are ready to incur additional costs related to the purchase of environmentally friendly engine oils. Of the drivers surveyed, only $26 \%$ declared a definite interest in engine oils marked as eco-friendly. Conditional interest (if the price was lower) was indicated by $28 \%$ of the respondents. Taxi drivers for whom a low oil price is very important or important in the purchasing process, to a large extent (58\% and 50\%) declared interest in environmentally friendly oils, assuming that their price would be lower. A definite preference for oils marked as environmentally friendly was declared by about $40 \%$ of the drivers for whom the price in the purchasing process is of little or no importance. Other respondents (46\%) declared no interest in such oils. Among them, $15 \%$ of the respondents stated that they did not trust eco-friendly products. Based on the results, a typical supporter of environmentally friendly engine oils is a driver of 40-50 years of age, driving a rather new car (under 10 years old) with low mileage (below 100k km), whereas a typical skeptic toward eco-labeled oils is a younger driver (under 30 years of age), driving an older car (above 10 years old) with rather high mileage (above $300 \mathrm{k} \mathrm{km}$ ). It is also worth mentioning one additional element environmentally differentiating the group of professional drivers from regular ones $-30 \%$ of the respondents (this is noticeably more than among regular drivers $-20 \%$ ) declared an oil change in their own garage or in the garage of their acquaintance. From an environmental point of view, the replacement of used engine oils in private garages is not environmentally welcome practice because it does not ensure proper and controlled collection and management. This clearly shows that more needs to be done to lower both percentages.

It is also important to provide the consumer with information that would make it possible to distinguish eco-friendly products from non-eco-friendly ones or products of unknown ecological status [13]. The most common is the use of eco-labels that can help consumers make decisions about pro-environmental products $[67,68]$. In the context of engine oils, such a label may not be sufficient, because in the group of regular drivers as well as in the group of professional drivers, over $50 \%$ of the respondents (52\% and 51\%, respectively) indicated that the information placed on the label was of no importance in their purchasing process. Therefore, it is necessary to conduct further research aimed at finding effective information channels on the pro-environmental aspects of engine oils.

\section{Conclusions}

Using a model-based clustering it was revealed that taxi drivers do not constitute a single homogenous group. They cluster into two groups with differing importance profiles as the BIC strongly favored a mixture model with two segments. Nevertheless, one of the segments clearly 
dominates because it comprises $81 \%$ of the respondents. These are drivers who primarily pay attention to technical oil parameters (viscosity, quality, OEM specifications) and rely on the recommendations of car manufacturers and employees of local garages. The importance of oil being environmentally friendly is a factor differentiating the subgroups. A definite interest in engine oils with the same technical parameters but additionally marked as environmentally friendly was indicated by $29 \%$ of the respondents from the first segment. In segment 2, this percentage was much lower and amounted to $15 \%$.

Results also suggest that the importance of the analyzed criteria affecting the choice of a particular oil brand varies between regular and professional drivers. The most important purchase criterion for drivers of both groups is the qualitative classification and viscosity classification; however, professional drivers indicate higher importance of brand loyalty, recommendations of oil sellers and recommendations of local garage and car service stations.

The analysis of consumer decision-making suggests that there is a need to put additional efforts to provide easily accessible and clearly visible technical specifications on the product label. The professional drivers comprising the largest segment were mainly guided by these specific data in the purchasing process. This was also true for drivers in the second segment but to a lesser degree. In both segments, unconditional preference for environmentally friendly engine oils was rather low suggesting that additional efforts to promote this kind of products may be necessary.

The analysis presented in this article has its limitations, which mainly result from the selection of one particular group of professional taxi drivers. It allowed for more focused conclusions but at the same time, it limited generalizability.

An interesting direction for future research may be the inclusion in the questionnaire questions about the harmful effects of engine oils on the environment and the analysis of the perception of these threats by the respondents representing both regular and professional drivers.

Author Contributions: Conceptualization: A.W., G.Z., K.F.; Methodology: A.W., G.Z., K.F.; Validation: A.W., G.Z.; Formal Analysis: A.W., K.F.; Investigation: A.W., G.Z., K.F.; Resources: A.W., G.Z., K.F.; Data Curation: A.W., G.Z., K.F.; Writing-Original Draft Preparation: A.W., G.Z., K.F.; Writing-Review and Editing: A.W., G.Z., K.F.; Visualization: A.W., G.Z., K.F.; Supervision: A.W.; Project Administration: A.W.; Funding Acquisition: A.W. All authors have read and agreed to the published version of the manuscript.

Funding: This research received no external funding.

Conflicts of Interest: The authors declare no conflict of interest.

\section{References}

1. Kollat, D.T.; Willett, R.P. Customer impulse purchasing behavior. J. Mark. Res. 1967, 4, 21-31. [CrossRef]

2. Olshavsky, R.W.; Granbois, D.H. Consumer decision making-fact or fiction? J. Consum. Res. 1979, 6, 93-100. [CrossRef]

3. Holbrook, M.B.; Hirschman, E.C. The experiential aspects of consumption: Consumer fantasies, feelings, and fun. J. Consum. Res. 1982, 9, 132-140. [CrossRef]

4. Engel, J.; Blackwell, R.; Miniard, P. Consumer Behavior (8th Eds.). N. Y. Dryden Press 1995, 8, 330-345.

5. Sweeney, J.C.; Soutar, G.N. Consumer perceived value: The development of a multiple item scale. J. Retail. 2001, 77, 203-220. [CrossRef]

6. Chen, A.; Lu, Y.; Wang, B. Customers' purchase decision-making process in social commerce: A social learning perspective. Int. J. Inf. Manag. 2017, 37, 627-638. [CrossRef]

7. Peter, J.P.; Olson, J.C. Consumer Behavior \& Marketing Strategy, 9th ed.; McGraw-Hill/Irwin: New York, NY, USA, 2010.

8. De Vries, N.J.; Reis, R.; Moscato, P. Clustering Consumers Based on Trust, Confidence and Giving Behaviour: Data-Driven Model Building for Charitable Involvement in the Australian Not-For-Profit Sector. PLoS ONE 2015, 10, e0122133. [CrossRef]

9. Yee, C.J.; San, N.C. Consumers' perceived quality, perceived value and perceived risk towards purchase decision on automobile. Am. J. Econ. Bus. Adm. 2011, 3, 47-57. 
10. Nagendramma, P.; Kaul, S. Development of ecofriendly/biodegradable lubricants: An overview. Renew. Sustain. Energy Rev. 2012, 16, 764-774. [CrossRef]

11. Pujari, D.; Wright, G.; Peattie, K. Green and competitive: Influences on environmental new product development performance. J. Bus. Res. 2003, 56, 657-671. [CrossRef]

12. Menguc, B.; Ozanne, L.K. Challenges of the "green imperative": A natural resource-based approach to the environmental orientation-business performance relationship. J. Bus. Res. 2005, 58, 430-438. [CrossRef]

13. Moser, A.K. Consumers' purchasing decisions regarding environmentally friendly products: An empirical analysis of German consumers. J. Retail. Consum. Serv. 2016, 31, 389-397. [CrossRef]

14. Maignan, I.; Ferrell, O.C. Antecedents and benefits of corporate citizenship: An investigation of French businesses. J. Bus. Res. 2001, 51, 37-51. [CrossRef]

15. Lombart, C.; Louis, D. A study of the impact of Corporate Social Responsibility and price image on retailer personality and consumers' reactions (satisfaction, trust and loyalty to the retailer). J. Retail. Consum. Serv. 2014, 21, 630-642. [CrossRef]

16. Kolk, A. Green reporting. Harv. Bus. Rev. 2000, 78, 15.

17. Lavorata, L. Influence of retailers' commitment to sustainable development on store image, consumer loyalty and consumer boycotts: Proposal for a model using the theory of planned behavior. J. Retail. Consum. Serv. 2014, 21, 1021-1027. [CrossRef]

18. Gurău Călin International green marketing: A comparative study of British and Romanian firms. Int. Mark. Rev. 2005, 22, 547-561. [CrossRef]

19. Knight, J. Acceptance of genetically modified food in India: Perspectives of gatekeepers. Br. Food J. 2008, 110, 1019-1033. [CrossRef]

20. Nath, V.; Kumar, R.; Agrawal, R.; Gautam, A.; Sharma, V. Green behaviors of Indian consumers. Int. J. Res. Manag. Econ. Commer. 2012, 2, 488-498.

21. Hansen, M.G. Environmental Engagement and Product Knowledge Among Consumers of Electric Light Bulbs in Albany, California; Published in ES196 May 2009, Senior ResearchSeminar, Environmental Sciences Group Major; University of California at Berkeley: Berkeley, CA, USA, 2009; pp. 1-12.

22. Rusin, M.; Gospodarek, J.; Nadgórska-Socha, A. The Effect of Petroleum-Derived Substances on the Growth and Chemical Composition of Vicia faba L. Pol. J. Environ. Stud. 2015, 24, 2157-2166. [CrossRef]

23. Wolińska, A.; Kuźniar, A.; Szafranek-Nakonieczna, A.; Jastrzębska, N.; Roguska, E.; Stępniewska, Z. Biological Activity of Autochthonic Bacterial Community in Oil-Contaminated Soil. Water. Air. Soil Pollut. 2016, 227, 130. [CrossRef] [PubMed]

24. Hsu, Y.-L.; Liu, C.-C. Evaluation and selection of regeneration of waste lubricating oil technology. Environ. Monit. Assess. 2011, 176, 197-212. [CrossRef] [PubMed]

25. Oliveira, C.M.; Magrini, A. Life Cycle Assessment of Lubricant Oil Plastic Containers in Brazil. Sustainability 2017, 9, 576. [CrossRef]

26. El-Fadel, M.; Khoury, R. Strategies for vehicle waste-oil management: A case study. Resour. Conserv. Recycl. 2001, 33, 75-91. [CrossRef]

27. Abdulkareem, A.S.; Afolabi, A.S.; Ahanonu, S.O.; Mokrani, T. Effect of Treatment Methods on Used Lubricating Oil for Recycling Purposes. Energy Sources Part Recovery Util. Environ. Eff. 2014, 36, 966-973. [CrossRef]

28. Zimmermann, T.; Jepsen, D. A framework for calculating waste oil flows in the EU and beyond - the cases of Germany and Belgium 2015. Resour. Conserv. Recycl. 2018, 134, 315-328. [CrossRef]

29. Hamilton, S.F.; Sunding, D.L. Optimal Recycling Policy for Used Lubricating Oil: The Case of California's Used Oil Management Policy. Environ. Resour. Econ. 2015, 62, 3-17. [CrossRef]

30. Chari, K.; Agarwal, A.; Agarwal, A.; Dang, G.; Giovanna, F.; Jagieta, S.; Wijeyekoon, S. Compendium of Recycling and Destruction Technologies for Waste Oils; United Nations Environment Programme: Osaka, Japan, 2012.

31. Zając, G.; Szyszlak-Bargłowicz, J.; Słowik, T.; Kuranc, A.; Kamińska, A. Designation of Chosen Heavy Metals in Used Engine Oils Using the XRF Method. Pol. J. Environ. Stud. 2015, 24, 2277-2283. [CrossRef]

32. Hamad, A.; Al-Zubaidy, E.; Fayed, M.E. Used lubricating oil recycling using hydrocarbon solvents. J. Environ. Manag. 2005, 74, 153-159. [CrossRef] 
33. Abdulkareem, A.S.; Odigure, J.O.; Abenege, S. Predictive Model for Pollutant Dispersion from Gas Flaring: A Case Study of Oil Producing Area of Nigeria. Energy Sources Part Recovery Util. Environ. Eff. 2009, 31, 1004-1015. [CrossRef]

34. Brussels, S.; Luxembourg, R. Recycling of used Mineral Oil. J. Mech. Eng. Process. Technol. 2001, 8, 67-81.

35. Rac, A.; Vencl, A. Ecological and Technical Aspects of the Waste Oils Influence on Environment. In Proceedings of the 3rd International Conference on DIPRE, Galaţi, Romania, 26-27 April 2012; Volume 12, pp. 1-7.

36. Singh, S.K.; Agarwal, A.K.; Sharma, M. Experimental investigations of heavy metal addition in lubricating oil and soot deposition in an EGR operated engine. Appl. Therm. Eng. 2006, 26, 259-266. [CrossRef]

37. Ramadass, K.; Megharaj, M.; Venkateswarlu, K.; Naidu, R. Ecological implications of motor oil pollution: Earthworm survival and soil health. Soil Biol. Biochem. 2015, 85, 72-81. [CrossRef]

38. Wolak, A.; Zajac, G.; Golebiowski, W. Determination of the content of metals in used lubricating oils using AAS. Pet. Sci. Technol. 2019, 37, 93-102. [CrossRef]

39. Lam, S.S.; Liew, R.K.; Jusoh, A.; Chong, C.T.; Ani, F.N.; Chase, H.A. Progress in waste oil to sustainable energy, with emphasis on pyrolysis techniques. Renew. Sustain. Energy Rev. 2016, 53, 741-753. [CrossRef]

40. Willing, A. Lubricants based on renewable resources-An environmentally compatible alternative to mineral oil products. Chemosphere 2001, 43, 89-98. [CrossRef]

41. Belz, F.; Peattie, K. Sustainability Marketing Strategies, Sustainability Marketing: A Global Perspective; Wiley \& Sons: Hoboken, NJ, USA, 2012; pp. 1-352.

42. Isenhour, C. On conflicted Swedish consumers, the effort to stop shopping and neoliberal environmental governance. J. Consum. Behav. 2010, 9, 454-469. [CrossRef]

43. Gutiérrez, N.L.; Valencia, S.R.; Branch, T.A.; Agnew, D.J.; Baum, J.K.; Bianchi, P.L.; Cornejo-Donoso, J.; Costello, C.; Defeo, O.; Essington, T.E.; et al. Eco-Label Conveys Reliable Information on Fish Stock Health to Seafood Consumers. PLOS ONE 2012, 7, e43765.

44. Hauser, M.; Nussbeck, F.W.; Jonas, K. The Impact of Food-Related Values on Food Purchase Behavior and the Mediating Role of Attitudes: A Swiss Study. Psychol. Mark. 2013, 30, 765-778. [CrossRef]

45. Streletskaya, N.A.; Liaukonyte, J.; Kaiser, H.M. Absence labels: How does information about production practices impact consumer demand? PLoS ONE 2019, 14, e0217934. [CrossRef] [PubMed]

46. Thøgersen, J.; Jørgensen, A.-K.; Sandager, S. Consumer Decision Making Regarding a “Green” Everyday Product. Psychol. Mark. 2012, 29, 187-197. [CrossRef]

47. Sammer, K.; Wüstenhagen, R. The influence of eco-labelling on consumer behavior-results of a discrete choice analysis for washing machines. Bus. Strategy Environ. 2006, 15, 185-199. [CrossRef]

48. Wolak, A.; Fijorek, K.; Zając, G.; Kumbar, V. What Drives Consumers in Poland and the Czech Republic When Choosing Engine Oil Brand? Entrep. Bus. Econ. Rev. 2019, 7, 165-184. [CrossRef]

49. Najmiec, A. Psychosocial working conditions of bus drivers. Occup. Saf.-Sci. Pract. 2012, 7-11.

50. Kiełbasa, P.; Juliszewski, T.; Pawłowicz, J.; Dróżdż, T.; Zagórda, M.; Sęk, S. Ergonomic evaluation of the working environment professional driver. Autobusy Tech. Eksploat. Syst. Transp. 2016, 17, 1030-1037.

51. Krzykała, F. An Outline of Transport Sociology; Wyd. AE w Pozaniu: Poznań, Poland, 2004; ISBN 83-7417-011-5.

52. Leisch, F. FlexMix Version 2: Finite Mixtures with. J. Stat. Softw. 2008, 28, 1-35.

53. Dempster, A.P.; Laird, N.M.; Rubin, D.B. Maximum Likelihood from Incomplete Data Via the EM Algorithm. J. R. Stat. Soc. Ser. B Methodol. 1977, 39, 1-22.

54. Leisch, F. FlexMix: A General Framework for Finite Mixture Models and Latent Class Regression in $R$. J. Stat. Softw. 2004, 11, 1-8. [CrossRef]

55. Kass, R.E.; Raftery, A.E. Bayes factors. J. Am. Stat. Assoc. 1995, 90, 773-795. [CrossRef]

56. Wolak, A.; Zając, G. An Empirical Study of the Variables Affecting the Frequency of Engine Oil Change in the Environmental Aspect. Rocz. Ochr. Srodowiska 2019, 21, 738-766.

57. Grün, B.; Leisch, F. FlexMix: An $\{R\}$ Package for Finite Mixture Modelling. R News 2007, 7, 8-13.

58. Fraley, C.; Raftery, A.E. How many clusters? Which clustering method? Answers via model-based cluster analysis. Comput. J. 1998, 41, 578-588. [CrossRef]

59. Hoyer, W.D. An Examination of Consumer Decision Making for a Common Repeat Purchase Product. J. Consum. Res. 1984, 11, 822-829. [CrossRef]

60. Hoyer, W.D.; Brown, S.P. Effects of Brand Awareness on Choice for a Common, Repeat-Purchase Product. J. Consum. Res. 1990, 17, 141-148. [CrossRef] 
61. Mourali, M.; Laroche, M.; Pons, F. Antecedents of consumer relative preference for interpersonal information sources in pre-purchase search. J. Consum. Behav. 2005, 4, 307-318. [CrossRef]

62. Biswas, A.; Roy, M. A study of consumers' willingness to pay for green products. J. Adv. Manag. Sci. 2016, 4, 211-215. [CrossRef]

63. Min, S.-H.; Lim, S.-Y.; Yoo, S.-H. Consumers' Willingness to Pay a Premium for Eco-Labeled LED TVs in Korea: A Contingent Valuation Study. Sustainability 2017, 9, 814.

64. Schäufele, I.; Hamm, U. Consumers' perceptions, preferences and willingness-to-pay for wine with sustainability characteristics: A review. J. Clean. Prod. 2017, 147, 379-394. [CrossRef]

65. Ali, A.; Ahmad, I. Environment Friendly Products: Factors that Influence the Green Purchase Intentions of Pakistani Consumers. Pak. J. Eng. Technol. Sci. 2016, 2, 84-117. [CrossRef]

66. Parsa, H.G.; Lord, K.R.; Putrevu, S.; Kreeger, J. Corporate social and environmental responsibility in services: Will consumers pay for it? J. Retail. Consum. Serv. 2015, 22, 250-260. [CrossRef]

67. Pedersen, E.R.; Neergaard, P. Caveat emptor - let the buyer beware! environmental labelling and the limitations of 'green' consumerism. Bus. Strategy Environ. 2006, 15, 15-29. [CrossRef]

68. Thøgersen, J.; Haugaard, P.; Olesen, A. Consumer responses to ecolabels. Eur. J. Mark. 2010, 44, $1787-1810$. [CrossRef]

(C) 2020 by the authors. Licensee MDPI, Basel, Switzerland. This article is an open access article distributed under the terms and conditions of the Creative Commons Attribution (CC BY) license (http://creativecommons.org/licenses/by/4.0/). 